\title{
Analisis Kestabilan Model Predator Prey pada Tanaman Bambu dan Giant Panda
}

Hikmawati Pathuddin

Universitas Islam Negeri Alauddin Makassar, hikmawati.pathuddin@uin-alauddin.ac.id

\begin{abstract}
ABSTRAK, Model Predator Prey merupakan suatu model yang menjelaskan interaksi antara dua atau lebih spesies yang terdiri dari mangsa dan pemangsa. Penelitian ini bertujuan untuk menganalisis model predator prey pada tanaman bambu dan giant panda. Metode yang digunakan adalah metode studi literatur untuk konstruksi model, penentuan titik kesetimbangan, dan menganalisis kestabilan. Hasil penelitian menunjukkan dua titik kesetimbangan yaitu $\left(-\frac{N}{a}, 0\right)$ dan $\left(\frac{c}{d}, \frac{a c+N d}{b c}\right)$. Titik kesetimbangan pertama tidak dianalisis sebab tidak relevan dengan kondisi dunia nyata di mana populasi bernilai negatif. Dari hasil analisis terhadap titik kesetimbangan kedua, diperoleh bahwa titik kesetimbangan tersebut stabil. Upaya penanaman bambu secara konstan tidak berpengaruh secara signifikan terhadap kestabilan titik kesetimbangan.
\end{abstract}

Kata Kunci: predator prey, titik kesetimbangan, kestabilan

\section{PENDAHULUAN}

Pada umumnya, dalam kehidupan nyata terdapat interaksi antar spesies dalam suatu ekosistem, sehingga keadaan populasi suatu spesies akan berbeda tanpa hadirnya spesiesspesies lain yang berinteraksi. Interaksi antar spesies tersebut dapat memberikan dampak positif, negatif, atau bahkan tidak berpengaruh bagi spesies-spesies yang berinteraksi. Model interaksi pemangsaan atau model mangsa pemangsa sederhana yang telah banyak dikenal adalah model Lotka-Volterra. Model LotkaVolterra disebut juga dengan model Predator Prey di mana terjadi interaksi antara pemangsa dan mangsa[1].

Panda, khususnya Giant Panda (Panda Raksasa), merupakan salah satu jenis hewan langka yang dilindungi. Sejak tahun 1990, Panda ditetapkan sebagai hewan dengan status terancam. Bahkan, pada tahun 2000-2002, diperkirakan hanya sekitar 1.600 ekor panda yang hidup di alam liar. Hal tersebut memunculkan kekhawatiran akan punahnya populasi hewan ini.
Meskipun secara taksonomi panda termasuk hewan karnivora, namun mereka lebih menyukai bambu[2]. Bahkan bambu telah menjadi sumber makanan utamanya[3]. Dalam sehari, mereka menghabiskan sekitar 14 jam waktunya untuk mengkonsumsi bambu. Mereka bahkan mampu menghabiskan $38 \mathrm{~kg}$ bambo per hari[4]. Artinya, kelangsungan hidup panda sangat bergantung pada tanaman bambu. Namun, seiring dengan berkurangnya jumlah populasi bambu yang disebabkan oleh berbagai hal, maka populasi panda juga ikut berkurang.

Salah satu upaya untuk melestarikan hewan ini adalah dengan pembentukan area konservasi dan penangkaran. Di tempat inilah panda dikembangbiakkan agar populasinya tidak mengalami kepunahan, Jika diasumsikan bahwa di tempat tersebut hanya ada panda dan juga bambu sebagai makanannya, maka akan ada satu masa di mana populasi bambu tersebut berkurang atau bahkan habis sebab terus menerus dimakan oleh panda. Dengan berkurangnya jumlah bambu, maka populasi panda dipastikan juga akan berkurang.

Pada paper ini, akan dibangun sebuah model matematika tentang interaksi antara dua spesies yaitu panda, khususnya Giant Panda (Panda Raksasa), dengan bambu. Di sini, akan diperlihatkan pengaruh perubahan populasi bambu terhadap perubahan populasi panda sehingga dari model ini dapat diupayakan agar populasi panda tetap ada, dan tidak mengalami kepunahan. Dalam model ini pula, akan dilakukan analisis kestabilan serta interpretasinya..

\section{TINJAUANPUSTAKA}

\section{Titik Kesetimbangan}

Diberikan system persamaan

$$
\dot{x}=f(x)
$$


Titik $x^{*}$ merupakan titik kesetimbangan jika $f\left(x^{*}\right)=0$. Titik kesetimbangan disebut juga titik ekuilibrium atau titik kritis.

\section{Pelinearan}

Misalkan diberikan sistem persamaan linear tidak linear

$$
\dot{x}=f(x)
$$

Dengan menggunakan ekspansi Taylor untuk suatu titik tetap, maka persamaan (2.2) dapat ditulis sebagai berikut:

$$
\dot{x}=J x+\xi(x)
$$

di mana $\xi(x)$ adalah suku berorde tinggi yang bersifat $\log _{x \rightarrow 0} \xi(x)=0$ dan

$$
J=\left[\begin{array}{ccc}
\left.\frac{\partial f_{1}}{\partial x_{1}}\right|_{x_{0}} & \mathrm{~L} & \left.\frac{\partial f_{1}}{\partial x_{n}}\right|_{x_{0}} \\
\mathbf{M} & \mathbf{M} \\
\left.\frac{\partial f_{n}}{\partial x_{1}}\right|_{x_{0}} & \mathrm{~L} & \left.\frac{\partial f_{n}}{\partial x_{n}}\right|_{x_{0}}
\end{array}\right]
$$

$\dot{x}=J x$ disebut pelinearan dari system tak linear pada persamaan (2.2)

\section{Nilai Eigen dan Vektor Eigen}

Diberikan matriks koefisien konstan $J$ berukuran $n \times n$, dan SPD linear tak homogen berikut:

$$
\dot{x}=J x+b
$$

Suatu vektor tak nol $x$ dalam ruang $\mathfrak{R}^{n}$ disebut vektor eigen dari $J$ jika untuk suatu skalar $\lambda$ berlaku:

$$
J x=\lambda x
$$

Nilai skalar $\lambda$ dinamakan nilai eigen dari $J$. Untuk mencari nilai $\lambda$ dari matriks $J$, maka persamaan (2.5) dapat ditulis kembali sebagai berikut:

$$
(J-\lambda I) x=0
$$

dengan $I$ matriks identitas. Persamaan (2.6) mempunyai solusi tak nol jika dan hanya jika:

$$
p(\lambda)=\operatorname{det}(J-\lambda I)=0
$$

Persamaan (2.7) disebut persamaan karakteristik dari matriks $J[5]$.

\section{Kestabilan Titik Ekuilibrium}

Suatu model populasi dengan $K$ spesies, yaitu $x_{1}, x_{2}, \ldots, x_{k}$ yang berinteraksi dalam suatu komunitas, dapat ditulis:

$$
\begin{gathered}
\frac{d x_{1}}{d t}=f_{1}\left(x_{1}, x_{2}, \ldots, x_{k}\right) \\
\vdots \\
\frac{d x_{k}}{d t}=f_{k}\left(x_{1}, x_{2}, \ldots, x_{k}\right)
\end{gathered}
$$

Kestabilan sistem ini dapat ditentukan dengan melihat nilai eigen pada saat dilakukan pelinearan dengan matriks Jacobi pada titik kesetimbangannya. Jika nilai eigennya semua negatif, maka titik kesetimbangan stabil.

\section{METODOLOGI}

Jenis penelitian yang digunakan adalah studi literatur untuk konstruksi model, penentuan titik kesetimbangan, dan menganalisis kestabilan. Secara umum, langkah-langkah penelitian adalah sebagai berikut.

1. Mengkonstruksi model berdasarkan fenomena dan asumsi-asumsi awal

2. Menentukan titik kesetmbangan model

3. Melakukan analisis kestabilan terhadap model yang telah dibuat

4. Menjelaskan interpretasi dari model

\section{PEMBAHASAN}

\section{Hasil Penelitian}

\section{Model Matematika}

Model matematika berawal dari adanya fenomena di sekitar kita. Dari fenomena itulah, kita dapat menyusun asumsi-asumsi yang dapat membantu untuk mengkonstruksi sebuah model yang kemudian dianalisis dan diinterpretasi sesuai dengan fenomena yang ada. Adapun 
bagan pembentukan model dapat dilihat sebagai berikut.

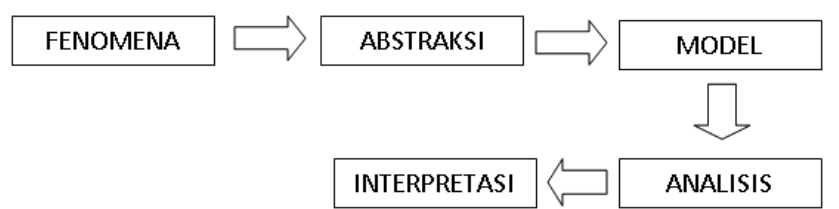

Gambar 1. Bagan Pembentukan Model

Dalam paper ini, model diawali dengan adanya fenomena binatang Panda yang sudah semakin langka. Panda sangat bergantung pada tumbuhan bambu, sebab bambu merupakan sumber makanan utama. Salah satu upaya untuk menjaga kelestrian panda adalah dengan mengirim panda-panda tersebut ke area konservasi. Jadi, dalam model yang akan dibuat, digunakan asumsi bahwa panda ditempatkan dalam sebuah lingkungan tertutup yang dalam hal ini tempat konservasi atau kebun binatang, yang di dalamnya hanya ada panda dan tumbuhan bambu.

Model interaksi antara populasi bambu dengan populasi panda yang telah dibangun adalah sebagai berikut:

$$
\begin{aligned}
& \frac{d B}{d t}=a B-b P B+N \\
& \frac{d P}{d t}=-c P+d P B
\end{aligned}
$$

dengan kondisi awal:

$B(t) \geq 0, P(t) \geq 0$

di mana:

$P(t)=$ populasi panda pada waktu $t$

$B(t)=$ populasi bambu pada waktu $t$

$a=$ laju pertumbuhan bambu, pada saat tidak ada $P$

$b=$ efek pemangsaan terhadap bambu oleh panda

$c=$ laju kematian panda, pada saat tidak ada bambu

$d=$ laju pertumbuhan panda saat terjadi interaksi dengan bambu $N=$ jumlah konstan bambu yang ditanam Parameter $a, b, c, d$ positif

\section{Titik Kesetimbangan}

Untuk menentukan titik kesetimbangan, maka $\frac{d B}{d t}=0$ dan $\frac{d P}{d t}=0$. Sehingga persamaan (4.1) menjadi:

$$
\begin{aligned}
& a B-b P B+N=0 \\
& -c P+d P B=0
\end{aligned}
$$

Persamaan (4.2) menjadi

$b P B=a B+N$ sehingga diperoleh $P=\frac{a B+N}{b P}$

Persamaan (4.3) menjadi $P(-c+d B)=0$ sehingga diperoleh :

$$
\begin{aligned}
P=0 \text { atau }-c+d B & =0 \\
B & =\frac{c}{d}
\end{aligned}
$$

Pada saat $P=0$, maka $P=\frac{a B+N}{b(0)}$

$$
a B+N=0
$$

$$
B=-\frac{N}{a}
$$

$>$ Pada saat $B=\frac{c}{d}$, maka $P=\frac{a B+N}{b P}$

$$
\begin{aligned}
& P=\frac{a\left(\frac{c}{d}\right)+N}{b\left(\frac{c}{d}\right)} \\
& P=\frac{a c+N d}{b c}
\end{aligned}
$$

Jadi, ada dua titik kesetimbangan yang diperoleh, yaitu: $\left(-\frac{N}{a}, 0\right)$ dan $\left(\frac{c}{d}, \frac{a c+N d}{b c}\right)$

\section{Analisis Kestabilan}

Akan dianalisis kestabilan dari titik-titik kesetimbangan yang diperoleh dengan menggunakan matriks Jacobi.

$$
J=\left(\begin{array}{cc}
a-b P & -b B \\
d P & -c+d B
\end{array}\right)
$$


Untuk titik $\left(-\frac{N}{a}, 0\right)$ tidak dianalisis sebab titik ini tidak menarik untuk ditinjau. Di sini terlihat bahwa $B$ bernilai negatif, hal ini tidak sesuai dengan asumsi bahwa jumlah populasi bernilai positif. Dalam dunia nyata, keadaan di mana jumlah populasi bernilai negatif tidak akan terjadi. Jadi, yang akan ditinjau hanya titik ekuilibrium kedua.

Untuk titik $\left(\frac{c}{d}, \frac{a c+N d}{b c}\right)$ :

$J=\left(\begin{array}{cc}a-b P & -b B \\ d P & -c+d B\end{array}\right)$

$J=\left(\begin{array}{cc}a-b\left(\frac{a c+N d}{b c}\right) & -b\left(\frac{c}{d}\right) \\ d\left(\frac{a c+N d}{b c}\right) & -c+d\left(\frac{c}{d}\right)\end{array}\right)$

$J=\left(\begin{array}{cc}a-\left(\frac{a c+N d}{c}\right)-\lambda & -b\left(\frac{c}{d}\right) \\ d\left(\frac{a c+N d}{b c}\right) & -\lambda\end{array}\right)$

dan Tanaman Bambu $(B)$ sebagai prey (mangsa). Diasumsikan bahwa Panda ditempatkan di sebuah area tertutup di mana hanya terdapat tanaman bambu yang merupakan makanan utama Panda. Dengan demikian, terjadi interaksi antar kedua spesies tersebut. Dari model yang telah dibentuk, terlihat bahwa pada saat tidak terdapat populasi panda, maka populasi bambu akan meningkat jumlahnya. Sebaliknya, pada saat tidak terdapat populasi bambu, maka populasi panda akan berkurang jumlahnya. Ketika jumlah bambu telah meningkat, maka Panda akan mempunyai makanan yang cukup untuk menopang pertumbuhan populasinya. Akibatnya, populasi bambu ini akan berkurang. Seiring dengan berkurangnya populasi bambu, maka populasi panda juga akan kembali berkurang. Oleh karena itu, dilakukan upaya penanaman bambu secara berkala dalam jumlah konstan $(\mathrm{N})$ agar jumlah populasi panda tetap terjaga.

Selanjutnya, dari analisis model

Persamaan karakteristik:

Diperoleh

$$
\lambda^{2}+\left(\frac{N d}{c}\right) \lambda+(N d+a c)
$$

$$
\lambda_{1}=-\frac{1}{2} \frac{N d-\sqrt{N^{2} d^{2}-4 a c^{3}-4 c^{2} N d}}{c}
$$

dan

$$
\lambda_{2}=-\frac{1}{2} \frac{N d+\sqrt{N^{2} d^{2}-4 a c^{3}-4 c^{2} N d}}{c}
$$

Karena nilai-nilai eigennya bernilai negatif, maka titik $\left(\frac{c}{d}, \frac{a c+N d}{b c}\right)$ stabil.

\section{Interpretasi}

Model yang diperoleh merupakan model sistem persamaan diferensial nonlinear, yaitu:

$$
\begin{aligned}
& \frac{d B}{d t}=a B-b P B+N \\
& \frac{d P}{d t}=-c P+d P B
\end{aligned}
$$

Pertama, akan dijelaskan model yang telah dibentuk. Model tersebut merupakan model predator prey atau mangsa pemangsa di mana Giant Panda $(P)$ sebagai predator (pemangsa) diperoleh titik kesetimbangan yang stabil yaitu $\left(\frac{c}{d}, \frac{a c+N d}{b c}\right)$. Artinya, jika diambil nilai awal tertentu untuk masing-masing populasi bambu dan panda pada daerah di sekitar titik kesetimbangan, maka dalam waktu yang cukup lama perubahan jumlah populasi bambu dan panda akan menuju titik kesetimbangan, yaitu populasi bambu akan menuju $\frac{c}{d}$ dan populasi panda akan menuju $\frac{a c+N d}{b c}$.

Jika $P>\frac{a c+N d}{b c}$ maka populasi bambu akan habis, tetapi ketika jumlah panda tepat sama dengan $\frac{a c+N d}{b c}\left(P=\frac{a c+N d}{b c}\right)$, maka pada saat itu populasi bambu tidak akan berubah. Begitu juga sebaliknya, jika jumlah bambu sangat kecil $\left(B<\left(\frac{c}{d}\right)\right)$, maka populasi panda akan habis, begitu juga jika jumlah bambu sangat besar $\left(B>\left(\frac{c}{d}\right)\right)$, maka populasi panda akan terus meningkat, tetapi ketika jumlah bambu tepat sama dengan $\frac{c}{d}\left(B=\frac{c}{d}\right)$, maka pada saat itu populasi panda tidak akan berubah (stabil). Jadi pada saat berada pada titik $\left(\frac{c}{d}, \frac{a c+N d}{b c}\right)$, maka dapat dikatakan bahwa model telah mencapai sebuah kesetimbangan dinamik. Hal ini 
menunjukkan bahwa kesetimbangan populasi telah stabil.

Selanjutnya, akan dianalisis pengaruh penanaman bambu secara berkala dalam jumlah konstan. Untuk konstanta $\mathrm{N}$ yaitu jumlah konstan pohon yang ditanam dapat dilihat bahwa jika $N=0$, maka persamaan karakteristik menjadi $\lambda^{2}+a c$, sehingga diperoleh nilai eigen $\lambda_{1,2}=$ $\pm \sqrt{-a c}$. Nilai eigen ini berupa bilangan kompleks di mana bagian real nya bernilai nol sehingga titik $\left(\frac{c}{d}, \frac{a c+N d}{b c}\right)$ dengan $N=0$ stabil netral. Hal ini berarti bahwa penanaman bambu dalam jumlah konstan tak terlalu berpengaruh secara signifikan terhadap kestabilan populasi.

Dari hasil ini, dapat diberi rekomendasi bahwa dengan hanya menanam bambu $(N)$ dalam jumlah kecil, sistem akan tetap stabil. Jadi, hal ini dapat mengurangi biaya yang digunakan dalam pelestarian Giant Panda.

\section{Simulasi Numerik}

Pada model ini, dilakukan simulasi numerik dengan nilai parameter $a=3, b=1, c=2, d=1, N=2 . \quad$ Hasil simulasi yang menunjukkan populasi tanaman bamboo dan giant panda dapat dilihat pada gambar 2 dan gambar 3 sebagai berikut.

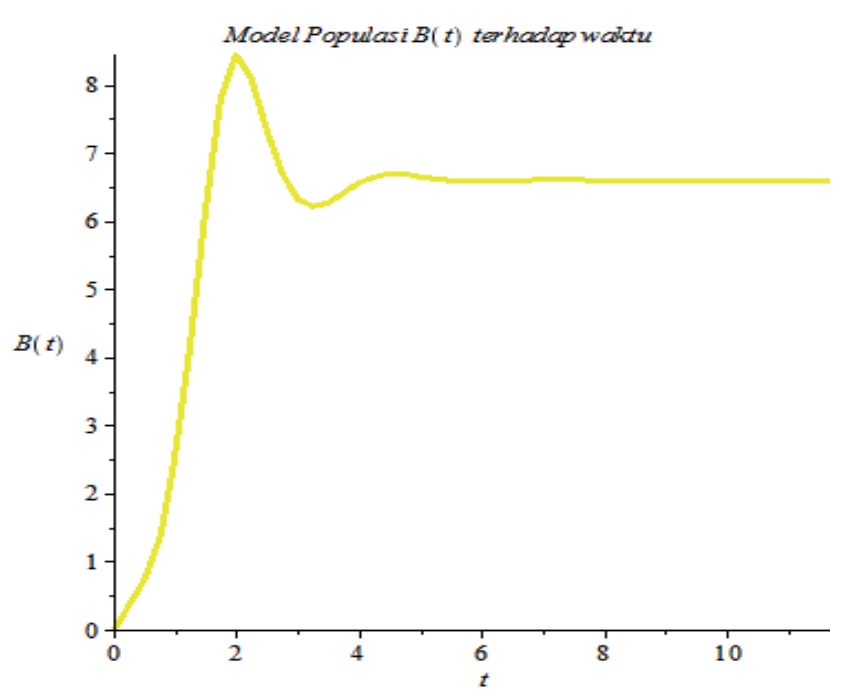

Gambar 2. Perubahan Populasi Bambu terhadap Waktu

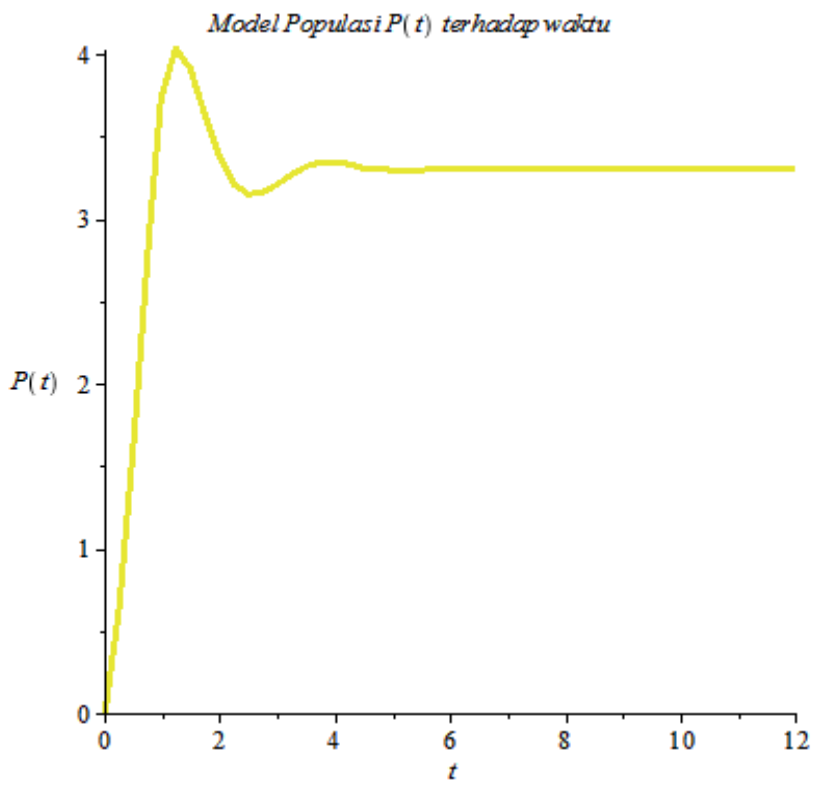

Gambar 3. Perubahan Populasi Panda terhadap Waktu

Dari simulasi numerik di atas, dapat dilihat bahwa pada waktu tertentu, populasi tanaman bambu dan giant panda akan stabil menuju ke titik kesetimbangan.

\section{KESIMPULAN}

Adapun kesimpulan yang diperoleh adalah:

1. Terdapat dua titik kesetimbangan pada model interaksi antara panda dan bambu, yaitu $\left(-\frac{N}{a}, 0\right)$ dan $\left(\frac{c}{d}, \frac{a c+N d}{b c}\right)$

2. Titik kesetimbangan $\left(-\frac{N}{a}, 0\right)$ tidak dianalisis karena nilai $B$ negatif sehingga tidak menarik untuk dianalisis, sedangkan titik kesetimbangan $\left(\frac{c}{d}, \frac{a c+N d}{b c}\right)$ stabil

3. Kestabilan model pada titik $\left(\frac{c}{d}, \frac{a c+N d}{b c}\right)$ berarti kelangsungan hidup panda akan tetap terjaga sehingga mereka terhindar dari kepunahan.

4. Jika $N=0$, maka diperoleh nilai eigen $\lambda_{1,2}= \pm \sqrt{-a c}$, yang berupa bilangan kompleks dengan bagian real bernilai nol sehingga titik $\left(\frac{c}{d}, \frac{a c+N d}{b c}\right)$ dengan $N=0$ stabil netral. Jadi, dapat diberi rekomendasi bahwa dengan hanya menanam bambu $(N)$ dalam jumlah kecil, sistem akan tetap stabil 
sehingga hal ini dapat mengurangi biaya yang digunakan dalam pelestarian panda.

\section{DAFTAR PUSTAKA}

[1] H. Richard, Mathematical Model (Mechanical Vibrations, Population Dynamics, and Traffic Flow. New Jersey: Prentice-Hall, Inc, 1977.

[2] E. S. Dierenfield, H. F. Hintz, J. B. Robertson, P. J. Van Soest, and O. T. Oftedal, "Utilization of Bamboo by the Giant Panda," J. Nutr., vol. 112(4), pp. 636-641, 1982.

[3] V. Hull, A. Shortridge, B. Liu, and S. Bearer, "The Impact of Giant Panda Foraging on Bamboo Dynamics in an Isolated Environment," Plant Ecol., no. 212.1, pp. 43-54, 2011.

[4] A. T. Mawarid, "Panda: Karnivora Pemakan Bambu," in Majalah 1000 Guru, vol. 5, no. 10, 2017, pp. 9-10.

[5] D. Purnamasari, Faisal, and A. J. Noor, "Kestabilan Sistem Predator-Prey Leslie," URNAL Mat. MURNI DAN Terap. Epsil., vol. 3, no. 2, pp. 51-59, 2009. 